\title{
Method for Educational Microcontent Production
}

\author{
Marcia Izabel Fugisawa Souza ${ }^{1}$, Tércia Zavaglia Torres ${ }^{2}$ \\ ${ }^{1,2}$ Research Group on Organization and Management of Digital Information, Embrapa Agricultural Informatics, Campinas, SP, Brazil, \\ Brazilian Agricultural Research Corporation (Embrapa)
}

\begin{abstract}
The article presents a comprehensive and detailed view of a method for educational microcontent production, obtained as a result of a doctoral thesis presented to the Faculty of Education of the University of Campinas, in the state of São Paulo, Brazil. The method systematizes didactically the practical orientations for producing digital content, to aid training actions aimed at multipliers from the areas of rural extension, technical assistance and technology transfer, with microtrainings through mobile devices. Nontraditional learning-teaching methodologies involve different actors of the educational process in different moments, from the programming of practical activities to the evaluation phase. In the proposed method, all actors participate in the didactic-pedagogical process. As such, apprentices/students and specialist/teachers play an active role, contrarily to traditional distance learning methodologies. The method of production of educational microcontent provides effective contributions for institutions of research, development and innovation (RDI), as the Brazilian Agricultural Research Corporation (Embrapa), owing to the incorporation of concepts and fundaments from continuous formation, in the modality of non-formal education, through microtrainings.
\end{abstract}

Keywords: Educational microcontent, microcontent, pedagogical architecture, language architecture, technological architecture.

\section{Introduction}

The current widespread use of mobile devices (cell phones and tablets) stems from the expansion of broadband connection and access to wireless networks, among other factors. In education, the progressive miniaturization of digital technologies and the development of mobile platforms offer new opportunities for students and teachers to keep improving their education with access through cell phones or tablets, from anywhere and at any moment. By applying the technological potential of mobile devices to educational activities, two modalities of teaching and learning came to be learning with mobility and microlearning. Among the countless challenges faced by these new types of learning, the production of educational content to support didactic and pedagogical activities aimed at students and apprentices with mobile devices stands out.

The production of pedagogical content under the logic of learning with mobility and microlearning assumes the adoption of innovative methodologies and practices that guide the process of producing microcontents ${ }^{1}$, since mobile media as cell phones and tablets require contents characterized by microcontents, i.e., small-sized contents of short length. Microcontents should meet the real needs of the apprentices, providing support for short, simple and complementary educational activities, as they are equivalent to objects of learning.

Educational microcontents can be composed of resources (media), such as text, sound, image, video, photo, image, drawing, map, game, infographic etc. The resources are suitable for mixing and combining the languages (sound, visual and verbal) present in the hybrid media part of mobile devices. These microcontents are fundamental to compose microtraining activities in continuous education programs in an organization of any nature.
In institutions of research, development and innovation (RDI), the demand grows for corporative education actions, including activities of distance training. The Brazilian Agricultural Research Corporation (Embrapa) is aware of the strategic importance of corporative education, especially in the segments of rural extension, technical assistance and technology transfer (TT), and desires educational solutions aimed at training and continuous education in the context of non-formal education.

As a result, Embrapa has developed and applied models for producing educational microcontent for virtual environments of learning with mobility, potentially applicable to the needs of microtraining in actions of continuous training. More specifically, a method for producing educational microcontent is being developed, which was the object of study of the doctoral research carried out by Souza [2], [3], with the Faculty of Education of the State University of Campinas.

In this article, an update for the method of production of educational microcontent for virtual environments of learning with mobility were defined. This text is the result of a comprehensive analysis of the activities that are inherent to the process of microcontent production (pedagogical architecture and language architecture), which led to the inclusion of a new process related to the technological aspects. The document presents a succinct description of all the activities of the processes of ${ }^{1}$ Microcontent, in this context, is considered a unit of learning that is "an atomic or elementary unit containing the basic elements required for the process of teaching and learning" [1]. Hence, the microcontent: cannot be subdivided into parts because its meaning could be lost; has limited size and duration; is selfcontained regarding goals and contents; is aimed at one or more goals of learning (or expected results).

Microcontent production. The detailed description of the activities is essential for the materialization of the educational microcontent, as it provides a methodological and operational foundation in the form of definitions, 


\section{International Journal of Science and Research (IJSR) \\ ISSN (Online): 2319-7064}

Index Copernicus Value (2013): 6.14 | Impact Factor (2014): 5.611

concepts, routes and indication of tools and actions.

\section{Production Process of Educational Microcontent}

The educational microcontent production process (EMPP) is based on three approaches: conceptual, analytical and methodological. Under the conceptual perspective, the method is a result of the analysis and the articulation of theoretical aspects from the fields of Pedagogy, Communication and Semiotics, which assemble key concepts for the production of educational microcontent. For the analytical approach, the method selected the principles determined by literature as fundamental for microcontent production: the pedagogy of Paulo Freire, social interactionist theory and hybrid languages. Under the methodology, it was sought to obtain a practical orientation for the process of microcontent production, with an operational scheme composed of processes, in an updated version of the method developed by Souza [2].

The inclusion of the process of technological architecture and the conceptual and operational details of the tasks inherent to the pedagogical architecture process are the main modifications of the current version. Hence, from now on the EMPP is composed of the following processes: pedagogical architecture process, language architecture process and technological architecture process, as shown in Figure 1. Although they are different, the processes are interdisciplinary and interconnected, as the description of the activities and tasks that compose each process will demonstrate.

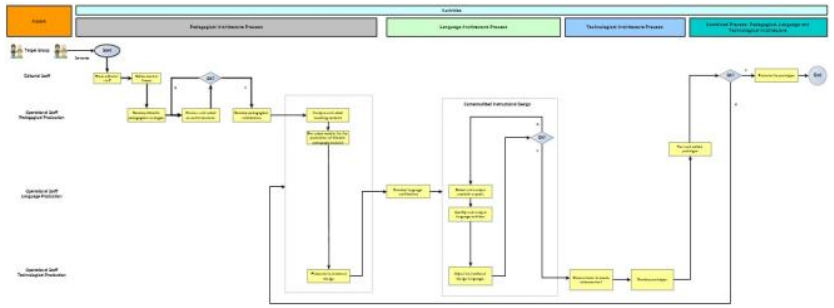

Figure 1: Processes of microcontent production: pedagogical architecture, language architecture and technological architecture.

\subsection{Activities of the Pedagogical Architecture Process}

The production of educational microcontent starts at the definition of the pedagogical architecture process, which assembles the main stages and activities that are part of the didactic-pedagogical process. The starting point is the elaboration of a pedagogical proposal that clearly meets the learning goals and purposes. These aspects, on their turn, must be part of the political and pedagogical project, in accordance with the strategic planning of the teaching institution. This process is on the same level of the language architecture and technological architecture processes.

\subsubsection{Form an Editorial Staff}

The first activity of the pedagogical architectural process is forming the editorial staff, carried out by the pedagogical staff. The editorial staff is in charge of the main decisions concerning the central theme and sub-themes that limit microcontent production for mobile devices, aiming at satisfying the information needs of the target group.

The composition of the editorial staff is based on the choice of technical specialists in the specific area of knowledge to which the demand of the course/training belongs. Thus, the editorial staff should be interdisciplinary and composed by: specialists on the theme; pedagogy professional; communication professional; design professional; information technology professional; information organization professional and representative of the information user of the theme.

The role of the editorial staff is to provide specific information and knowledge from the related areas of knowledge for all the members responsible for microcontent production, to ensure the production is carried out in a systematic and integrated manner, favoring the choice of essential information/contents that enable people to learn while accessing them.

The editorial staff ensures the quality of the information and pedagogical content that are being produced for the many interested groups. Therefore, the staff must aim at creating an interdisciplinary staff constituted of researchers, specialists and analysts of different areas of work of the company or outside of it.

\subsubsection{Define Central Theme and Sub-themes}

The second activity of the pedagogical architecture process is the definition of the central theme and sub-themes that will integrate the microcontent, performed by the editorial staff. It is highly important to make a good choice for the central theme and sub-themes linked to it, for they provide the essential contents defined in the pedagogical project of the course/training and the mental model followed in the stage of instructional design will be based on this choice. Thus, as a starting point the following criteria can be adopted for choosing the central theme of the microcontents: a) meeting social interest; b) meeting the demand identified by the pedagogical proposal of the course/training; c) transversality; d) conceptual comprehensiveness etc.

The definition of the central theme and sub-themes requires the previous identification of one or more elements of convergence around which the central theme can be worked. The elements of convergence generate the sub-themes, which are worked in an interdisciplinary, complementary and transversal manner regarding the central theme and promote a better understanding of the microcontent that will be produced. This action is highly important for microcontent production for it is the focal point in which content will circulate. Thus, as an example, the central theme environment can be discussed using water as an element of convergence. The sub-themes referring to the central theme and to the element of convergence are identified through the interdisciplinary approach for the element of convergence. In this way, the environment (central theme) would be worked from the element water (element of convergence), and the

\section{Volume 4 Issue 11, November 2015}




\section{International Journal of Science and Research (IJSR) \\ ISSN (Online): 2319-7064}

Index Copernicus Value (2013): 6.14 | Impact Factor (2014): 5.611

sub-themes would be the different interdisciplinary perspectives that are inserted in the element of convergence, such as biological, economical, geopolitical and environmental aspects.

\subsubsection{Develop Didactic-Pedagogical Strategies}

The third activity of pedagogical architecture is the development of didactic- pedagogical activities to work on the central theme of the microcontents that will be produced. This activity should structure the ways people will become interested in the contents that will be inserted into the microcontents. Didactic strategies are techniques that make contents easier to assimilate, as well as easier to link to the central theme that limits microcontents for the people that will access them. The use of these strategies will enable members of the staff that will produce the microcontent to see the many existing intersections between the central theme and the many areas of knowledge that are part of it.

A didactic-pedagogical strategy is any action aimed at challenging or enabling people to understand the central theme through the microcontent. With that purpose, the theme should be transformed into more specific contents (sub-themes) to facilitate the access of people to the development of mental operations aimed at its comprehension/assimilation. Therefore, the didacticpedagogical strategy is essential as it organizes the mental processes that enable people to understand the information of the contents that will be transported for the format of the microcontent. These strategies promote a learning process that considers people as active beings, i.e., builders of knowledge. They help people become aware, exercise, build, make their ideas and thoughts more receptive, and break mental barriers that prevent them from creating new assessments on the theme.

Didactic-pedagogical strategies are the construction of actions that seek to develop the main mental operations of people: a) comparison, b) observation, c) imagination, d) data obtaining and organization, e) elaboration and confirmation of hypotheses, f) classification, g) interpretation, h) criticism, i) search for suppositions, j) application of facts and principles to new situations, k) planning research projects, l) analysis and decision making and $\mathrm{m}$ ) construction of syntheses/summaries.

As didactic-pedagogical strategies are detached from the goal of the microcontent production, they can only be outlined after the central theme and sub-themes that will compose the microcontent are defined, and consequently after the objective of the learning that is to be attained through microcontent production is clearly established.

Hence, didactic-pedagogical strategies explore ways, manners, means and practices that single out certain forms of thought to guide people, favoring the construction of a comprehensive view on the theme that will be adopted by the microcontent. The established strategies should respect the favorable conditions, in order that people execute/do something from what they assimilated during the contact they had with the microcontent.
Microcontents should be developed from didacticpedagogical strategies. The chosen strategy should necessarily be led to one or more specific technological media/tools. The choice of the technological media/tools that will compose the didactic-pedagogical strategy will be made in Activity 2.2.1 of the language architecture process, considering the three elements (reference, meaning and interpretation) of the analysis of the semiotic aspects.

Based on studies by Anastasiou and Alves [4], some possible strategies for the production of microcontent are: lecture through dialogue; text study; portfolio; brainstorming; conceptual map; directed study; discussion list; solution of problems; phillips 66; group of observation and verbalization; dramatization; seminar; case study; simulated jury; symposium; panel; forum; workshop or laboratory; study of the environment; teaching with research.

\subsubsection{Discuss and Select Essential Contents}

The fourth activity in the pedagogical architecture process encompasses assembling, discussing and selecting support contents for the central theme that are considered essential sources for the elaboration of microcontents. Support contents are information resources that, once selected, should be analyzed under different perspectives (in order to form new possibilities for them to be worked), with the purpose of expanding the number of users and their understanding, trying to identify possible interconnections between the different areas of knowledge.

To achieve a good selection of contents to be worked with, considering the didactic-pedagogical strategies chosen on the previous stage, firstly, it is necessary to consider how they will be approached. The epistemological approach of knowledge construction that will be adopted to work on the contents should be analyzed. The form how content is constructed can lead to a higher probability of people assimilating it.

Hence, together with content selection, it is extremely important to discuss which are the epistemological foundations to be used for working on the contents (social interactionist, behaviorist, vygotskian etc.). Once the approach is selected, content selection is carried out, which should also be in accordance with the didactic-pedagogical strategies defined in the previous stage. The selection of support contents for microcontent production should be analyzed through the following actions: a) bibliographical survey focused on the central theme defined by the editorial staff; b) separating the selected bibliographical material according to the description of the previous item, considering the didactic-pedagogical strategies constructed in Activity 2.1 .3 ; c) analysis and discussion of the relevance and conformity of the selected materials, as well as their capacity of being linked to the other contents that will be part of the microcontent; d) classification of the selected material, considering the didactic-pedagogical strategies, according to Chart 1. Matrix: knowledge dimension and cognitive process dimension, presented below. With that purpose, Bloom's taxonomy should be followed, which will help create a hierarchy of the contents found in the selected materials, 


\section{International Journal of Science and Research (IJSR) \\ ISSN (Online): 2319-7064}

Index Copernicus Value (2013): 6.14 | Impact Factor (2014): 5.611

according to the three main domains (cognitive, affective and psychomotor) that need to be acquired by people in order for them to learn. Each learning domain has a level of development of the contents, and thus need to be arranged in a specific form to facilitate learning and metacognition.
A good instructional material should be selected as a foundation for microcontent production, so that the six cognitive processes defined by Bloom are covered, as well as the four types of knowledge necessary for learning, as presented in Chart 1 below:

\begin{tabular}{|l|l|l|l|l|l|l|}
\hline $\begin{array}{l}\text { Knowledge } \\
\text { dimension }\end{array}$ & \multicolumn{5}{|c|}{ Cognitive process dimension } \\
\hline & Remembering & Unterstanding & Applying & Analyzing & Evaluating & Creating \\
\hline Factual & Video 1 & Text 2 & Blog Interview 1 & Video 2 & Activity 1 & Activity 7 \\
\hline $\begin{array}{l}\text { Conceptual } \\
\text { (Principles) }\end{array}$ & Text 1 & Podcast 3 & Scientific Article 4 & Text 2 & Activity 2 & Activity 7 \\
\hline Procedural & & Field Day 2 & News Report 2 & Activity 8 \\
\hline Metacognitive & & & Text 3 & News Report 1 & Activity 8 \\
\hline
\end{tabular}

Chart 1: Matrix: knowledge dimension and cognitive process dimension.

Source: Ferraz and Belhot [5], adapted by the authors.

Each selected material should be linked to a single didacticpedagogical strategy. It is important not to use the same material in another strategy, for that would prevent the content from becoming an aesthetic object (the object from the Web that attracts people because it provides complementary information, not the same information arranged in a different manner). The selection of the teaching material should be done comprehensively and carefully, starting from the repository of Embrapa, but different sources (institutions and/or authors) should be analyzed as well in the search for text, hypertext, video, audio, games etc., which will form the resource base to support the elaboration of the microcontent.

\subsubsection{Develop Pedagogical Architecture}

The fifth activity of the pedagogical architecture process synthetizes and models in three stages the essential actions inherent to the pedagogical and instructional aspects that should be considered in microcontent production, which are here defined by the following sub-activities: a) discuss the matrix chart elaborated in Activity 2.1 .4 with the editorial staff (discuss and select essential contents); b) pre-selection of technological media/tools to be used to produce microcontent in different languages; c) elaboration of the contextualized-instructional design (CID), which consists in detailing instructional design and which should encompass the phases of analysis, design and development.

\subsubsection{Analyze and Select Didactic Material}

This is a stage of Activity 2.1.5 of the pedagogical architecture process, which is preceded by the discussion of the matrix chart produced in Activity 2.1.4 (Chart 1). In this stage, it was carried out a comprehensive analysis of the previously selected support content according to the matrix chart and the approval of the editorial staff. The contents inserted in each technological media/tool are analyzed, and those that will be used in microcontent production are selected.

The selection of the didactic material should follow these criteria rigorously: a) meet the demand of microcontent production; b) provide information that converge to the central theme of the microcontent; c) provide transversal information; d) provide conceptually comprehensive information; e) involve the participation of specialists of many domains of knowledge to ensure the systemic and integrated perspective of the contents that are related to microcontent production; f) evaluate the quality of the collected information, considering the criteria [These criteria refer to observing if the collected information represent correct concepts and/or an appropriate theoretical view; if they cover the universe of interest that will be addressed to produce the microcontent; if it contains all the necessary information for microcontent production; if they are stable over time and if they are in conformity with the educational intention required for the production of the microcontent; if they are detailed and enable relations with other information; if they represent the essence of the central theme that will be explored to produce the microcontent and if they are current for the context in which they will be used] of precision, completeness, structuring, relevance, credibility and the present time.

\subsubsection{Pre-select Media to Produce Microcontent}

The pre-selection of technological media/tools that will be used to produce the microcontent(s) is a decision related to the proposed instructional design. Hence, the first step is to consider the indication of the matrix chart of the knowledge and cognitive dimensions of Bloom's taxonomy, proposed in Activity 2.1.4 (Chart 1). This task contributes to the production of the media that will be part of all microcontent that will be produced.

The media chosen for microcontent production should be first and foremost free access tools (open source) and preferentially free, in order that customization and reutilization are allowed. Moreover, the tools should have a low cost and therefore be accessible in order to facilitate permanent updates and prevent issues related to versions becoming obsolete (see more details about this aspect in item

\section{Volume 4 Issue 11, November 2015}




\section{International Journal of Science and Research (IJSR) \\ ISSN (Online): 2319-7064}

Index Copernicus Value (2013): 6.14 | Impact Factor (2014): 5.611

2.3.1. - Choosing tools to create microcontents). The preselection should be preceded by an analysis of the matrix chart (resulting from Activity 2.1.4), which indicates the types of technological media/tools for each selected content. However, this does not imply that the original media of the selected material will be adopted to produce the microcontent, especially since the rigorous analysis of which technological media/tool(s) will produce the microcontent(s) should be carried out in Activities 2.2.1 and 2.2.2 of the language architecture process. As a result, the original media of the selected content may not be kept when microcontent is produced, i.e., it is possible for instance that a video has only the image or information that is important to produce the microcontent. In this case, it was elaborate the microcontent in another media, using part of the images or information found on the video that was originally selected.

In the case of using microcontent for microtraining through mobile devices, one or more media will be produced from a central theme, and they will be part of several media in which the microcontents will be inserted. In this media, the central theme will be worked on through the format of the microcontent in a complementary way in different media and under many perspectives. For that reason, the selection of the technological media/tools to be adopted in the production of the microcontent should be rigorously conducted, using the analysis of the three elements of the semiotic aspects (Activity 2.2.1 of the language architecture process), as microcontent can be placed into different types of media. Each type of media must go through a different treatment when receiving the microcontent, in order that the intention of the pedagogical proposal and the goals aimed with its dissemination are met. Choosing the wrong type of media can make the content uninteresting for the interactor that accesses the microcontent, making them unmotivated and indirectly compromising the result expected from mobile learning. For each type of media, the following issues should be considered: a) available time and space for its execution; b) access conditions and desires of the interactors which will use the microcontent and which are the target of the information dissemination.

The main steps for selecting media are: a) identify the required media attributes to meet the microcontent proposal; b) identify the characteristics of the interactors that will access the microcontent, which are the target of information dissemination, in order to conduct a selection focused on their interests; c) identify characteristics of the environment of information dissemination to analyze if the chosen media are the most appropriate; d) identify economic or organizational factors that may affect the viability of certain media.

\subsubsection{Elaborate a Contextualized-Instructional Design}

This is a task of Activity 2.1.5 of the pedagogical architecture process, which consists in detailing instructional design, with the phases of analysis, elaboration and development of the instructional design of the microcontent, which are described below:

\section{a) Instructional Analysis}

The first stage of the instructional design of the microcontent involves aspects related to the identification of learning needs, the characterization of apprentices, determining constraints and providing solutions. The following items should be identified: the needs and demands of information and educational content; why the educational action that involves the offer of microcontent is carried out in the proposed environment and format; the level of knowledge of students regarding the theme to be presented by the microcontent, i.e., what they already know and what they need and want to know; determining in advance possible technical constraints that may occur during the preparation of the microcontent, considering the expected deadlines for the development and implementation of the object of design; cultural issues and previous educational experiences of apprentices, linked to different conceptions of teaching and learning, since it may influence the acceptance of the microcontent proposal; if the action proposed by the microcontent is appropriate to satisfy the determined needs, in accordance with the declared constraints. The professionals elaborating the didactic content and the instructional designer of the microcontent are responsible for this first phase of the design.

\section{b) Instructional design}

The second phase of the instructional design of the microcontent specifies the object of learning (microcontent), understanding the planning and the design of the didactic situation itself. This phase includes: mapping and sequencing the contents that will be worked (Activity 2.1.4), definition of learning strategies and activities to achieve the goals that were set (Activity 2.1.3) and pre-selecting the most appropriate technological media/tools (Sub-activity 2.1.5.2). The pre-selection is merely indicative, as the selection itself will be based on a more rigorous analysis of the semiotic aspects in Activities 2.2.1 and 2.2.2 of the language architecture process.

To perform the second phase of the design, the aforementioned elements should be assembled (content mapping and sequencing, learning strategies and activities and pre-selected technological media/tools) in an instructional design matrix that guides the execution of this activity, starting from the definition of the following elements: goals, roles, activities, length and period, contents, pre-selected media/tools and evaluation.

Still in the design phase, storyboarding (script) is used to complement the instructional design matrix that assembles the key pedagogical elements. With storyboarding, it is possible to sketch graphically the sequence of actions and detail the form and the resources that will be used in the execution of the object of learning (microcontent). The professionals elaborating the didactical content and those involved with the instructional designer of the microcontent are responsible for this second phase of the design.

c) Development of instructional design

The construction and adaptation of the microcontent occurs 


\section{International Journal of Science and Research (IJSR) \\ ISSN (Online): 2319-7064}

Index Copernicus Value (2013): 6.14 | Impact Factor (2014): 5.611

in this third phase of the elaboration of the instructional design. In this stage, the rules to be used and/or adapted in the execution of the object of learning (microcontent) were defined. The planned actions previously specified in phase two (instructional design) are put into practice. The development of the design demands the adoption of content and metadata packaging standards, which should ensure the reutilization, interoperability, accessibility etc. Issues concerning interface should be tackled in this phase, such as concerns with: legibility, type, size, color, hypertext (textual interface); details as icons, buttons, images, animations, videos (graphic interface). A simple and intuitive interface ensures usability for the user. The user should remain informed about their location, how they got there and how to leave. Coherence and uniformity of language and information should also be ensured. Lastly, the production and the test of the microcontent under the perspective of pedagogical architecture and especially under the perspective of instructional design are carried out in this phase. The professionals in charge of the script, illustration, web design, software, review, content production (content specialist) and the instructional designer are responsible for this third phase of the design.

The phases of implementation and evaluation of the instructional design will be conducted in Activity 2.3.1 of the technological architecture process, which consists in testing and validating the prototype, and in Activity 2.5 (an action that occurs separately from the three mentioned processes), which evaluates the prototype.

\subsection{Activities of the Language Architecture Process}

This process assembles the main activities related to the production of educational microcontent for mobile devices, guided by semiotic aspects and emphasizing the main characteristics of hybrid languages. This process analyzes the need to adjust the design project presented in the process of pedagogical architecture, and is in accordance with the processes of pedagogical architecture and technological architecture.

\subsubsection{Select and Analyze Semiotic Aspects}

The first activity of the process of architecture of languages is the selection and analysis of the semiotic aspects that make the educational microcontent (sign) be considered an object of aesthetics - an object capable of provoking a direct impact in the experience of people. To conduct this analysis, the starting point should be the instructional design elaborated in activity 5.3 of the pedagogical architecture process.

The analysis of the semiotic aspects focuses on the three elements of the representation of the microcontent (sign): the element of meaning (sign), the element of reference (object of the sign) and the element of interpretation (interpretant of the sign). These three elements are directly related to the triadic nature of the signs, which have a structure defined by the three elements: sign, object and interpretant.

- Meaning - the microcontent should be analyzed through its meanings, what it indicates, what it refers to or what it represents, its quality, its concrete existence, its character of law, its internal properties (iconic aspect, indexical aspect and symbolic aspect).

- It is the method how the microcontent, as a sign, gives meaning to its referent, which is the object (the collaborative learning practices with mobility), i.e., how it refers to the microcontent itself, its meaning.

- Iconic aspect - In this aspect, the microcontent should be analyzed by its quality as a product, or better yet, by its graphic and visual quality, its design, form, colors, signals, size etc. The analysis of the iconic aspect of the microcontent will be responsible for the first impressions it will cause on the user. "[...] moving cameras are more effective to portray running water than fixed cameras, which are more effective for showing a degraded environment". [6].

- Indexical aspect - In the microcontent (sign), this aspect should be observed in the analysis regarding the existence of the object, i.e., the relationship of the sign with the object, since the sign represents the existing object, but not the object as a whole. In videos or photos, the indexical aspect is dominant because it shows what is real, what in fact exists, even if it only portrays part of reality. For instance: a photo of a tree, which has an image that exists outside the photo and regardless of it. The image in the photo has the power to indicate that tree in its existence. Therefore, under the indexical aspect, the microcontent should be analyzed as an object that exists in a determined time and space. Its characteristics, its qualities (shape, size, dimension and format) should be identified, which are then seen as a function of manipulation and constant use.

- Symbolic aspect - In the microcontent (sign), this aspect should be observed through the values that will be transmitted through verbal discourse (narrative), in the case of a video. "(Verbal) is highly necessary in educational videos since it examines and even constructs an argument on the topic being discussed. When the target is a younger audience to whom the construction of an argument is too abstract, the video employs narrative discourse. In this case, the argument is constructed using as an example a story that may be seen as a life lesson [6].

- Reference - Analyze the microcontent based in its object (referent). Firstly, ask to what the sign refers to. Aim at identifying who is the referent of the sign, i.e., that which corresponds to its object (in this case, the collaborative learning practices with mobility). Identify the ways through which the referent (object of the sign) is present in the sign (microcontent).

- Qualitative modality - in the case of a video, for instance, the analysis should focus on details as the [...] quality of takes, framings, points of view and camera movements, on the tone of the discourse that follows the image, on the quality of the voice etc. - in aspects related to the mere appearance of the videos, the way they appear, its colors, its movements, scene length, cuts, image contrast [6].

- Duration and resolution size are decisive elements for the elaboration of the microcontent, due to the specificities of the device, the mobility aspect and its target group, therefore it is necessary to consider, for instance, the length of the takes, the types of takes, the integration between speech and image or lack thereof, the tone of the speech, soundtrack etc. The other elements that are appropriate for

\section{Volume 4 Issue 11, November 2015}




\section{International Journal of Science and Research (IJSR) \\ ISSN (Online): 2319-7064}

Index Copernicus Value (2013): 6.14 | Impact Factor (2014): 5.611

video production cannot always be used in the case of microcontents.

- Existential modality - the analysis should be based on the understanding that an existent (a sign, i.e., a microcontent) can only exist through its qualities. For instance, a video can only exist through its qualities, i.e., through its own characteristics. In addition, these characteristics on their turn constitute the specific and peculiar qualities of image and speech that are embodied in the existent. The analysis of the qualitative aspects should respect the specificity of each existent, understood here as sign.

- Generic modality - the analysis of the sign (microcontent) should follow a typology, for instance: video documentary, video report, didactical video, educational video, and informative video.

- Interpretation - the microcontent (sign) should be analyzed based on the effects it produces, on its relationship with the interpretant (user), on the types of interpretation that it (sign) can evoke from the interpretant (the user). These effects, called interpretative, will vary according to the way the sign (microcontent) will represent its object (the collaborative learning practices). In this element of interpretation, the existence of three levels of interpretants should be considered, each corresponding to different levels of realization: immediate, dynamic and final. Thus, in this stage of the analysis of the semiotic aspects of the microcontent, the purpose is to identify the occurrence of:

- Immediate interpretant - which reveals the interpretative potential of the sign, i.e., the target group of the microcontent, for instance.

- Dynamic interpretant - denotes the effects a sign produces in an interpretant, such as: a) emotional effect - reveals something about the quality of the feeling that the sign can evoke on the interpretant; b) energy effect - evokes an active reaction in the receptor (student), through intellectual or physical effort; c) logical effect internalizes a rule of conduct, a code of a cultural convention to interpret its meaning.

- Final interpretant - the effect the sign would produce in any mind, if it were possible for the sign to produce all the dynamic interpretants in a final and exhaustive way. If this is impossible, the progress of the final interpretant will always be constant, and its evolution, infinite.

\subsubsection{Identifying and Analyzing Matrices of Languages}

The second activity of the process of architecture of languages focuses on: identifying the three matrices of language and thought present in the microcontent and analyzing the mixtures and combinations of these matrices, which is characterized as hybrid languages. To execute this activity, the following script is proposed:

- For the sound matrix: a) identify aspects of the sound matrix in the microcontent, such as: manifestations of language through speech, music, sound (without speech), noise etc.; b) analyze the mixtures of the matrices and their combinations, for instance: sound (sound matrix) - image (visual matrix) - text (verbal matrix); c) analyze the occurrence of hybrid languages such as: sound-verbal languages (music); verbal-visual-sound languages (videos); visual-verbal languages (editorial cartoons and comics).
- For the visual matrix: a) identify aspects of the visual matrix in the microcontent, such as manifestations of the language through colors, shapes, movement, dynamic, lines, volumes, gestures, drawing, painting, picture, map, diagram etc.; b) analyze the mixtures of matrixes and their combinations, for instance: image (visual matrix) - sound (sound matrix) - text (verbal matrix); c) analyze the occurrence of hybrid languages, such as: sound-verbal languages (music); verbal-visual-sound languages (videos); visual-verbal languages (editorial cartoons and comics).

- For the verbal matrix: a) identify aspects of the verbal matrix in the microcontent, such as manifestations of the language through text/hypertext (descriptive, informative, narrative and discursive); b) analyze the mixtures of the matrixes and their combinations, such as: text (verbal matrix) - image (visual matrix) - sound (sound matrix); c) analyze the occurrence of hybrid languages, such as: sound-verbal languages (music); verbal-visual-sound languages (videos); visual-verbal languages (editorial cartoons and comics).

\subsubsection{Adjust the Contextualized-Instructional Design to the Languages}

The third activity of the language architecture process refers to the adjustments that need to be done in the digital technological media/tools that were pre-selected in instructional design. The idea is to alter them if they do not match the analyses of Activities 2.2.1 and 2.2.2 of the language architecture process. The purpose is to verify if the proposal of the technological media/tools previously defined by instructional design meets the semiotic assumptions of a didactic-pedagogical object. If it does not meet them, the problem is identified and, if it is the case, the process of architecture of languages is restarted

\subsection{Activities of the Process of Technological Architecture}

This process consists in the activity of prototyping the educational microcontent, incorporating the elements discussed in the activities proposed in the processes of pedagogical architecture and architecture of languages. This process aligns with the processes of pedagogical architecture and architecture of languages.

\subsubsection{Choose Tools to Create Microcontent}

In any modality of education, especially in education that is not face-to-face, it is necessary and important to establish technological resources and methodological procedures that effectively ensure that the educational dialogue among those involved occurs in the best possible way. By corroborating this logic, Sanchez [7] argues that technologies chosen to aid distance teaching should be open and interactive to enable the participation of people and the establishment of new relationships with materials and contents and with the other apprentices participating in the educational process.

Hence, the elaboration of the contextualized-instructional design (Activity 2.1.5.3) and its adjustment to the process of architecture of languages (Activity 2.2.3) are the main materials that the operational staff of the process of

\section{Volume 4 Issue 11, November 2015}




\section{International Journal of Science and Research (IJSR) \\ ISSN (Online): 2319-7064}

Index Copernicus Value (2013): 6.14 | Impact Factor (2014): 5.611

technological architecture should follow to choose the tool(s) that will be used to produce and/or send the microcontent which will be made available for the apprentices.

Moore and Kearsley [8] state that there is no single technology capable of completely meeting the necessary requirements of an instructional design. This affirmation becomes even more concrete when the product is a microcontent that will be made available in a mobile device. In these cases, the operational staff of the technological architecture process is in charge of choosing the media/tools that satisfy the needs of different actors (apprentices, teachers/instructors and actors of the institution that offers the microtraining), especially as the learning environment is not controlled. Hence, the choice of technological tools for distance teaching should combine a mixture of media and tools to increase the chances of promoting different learning styles for the apprentices, as Moore and Kearsley [8] highlighted.

As a result, the staff in charge of the technological architecture of the microcontent production should choose free access tools (open source) and preferentially free, in order that customization and reutilization are allowed. Moreover, the tools should have a low cost and therefore be accessible in order to facilitate permanent updates and prevent issues related to versions becoming obsolete. Accessibility should also be considered, i.e., the tools should be used in any computer and in different platforms.

Although these requirements are essential for microcontent production, they are not sufficient to produce an open
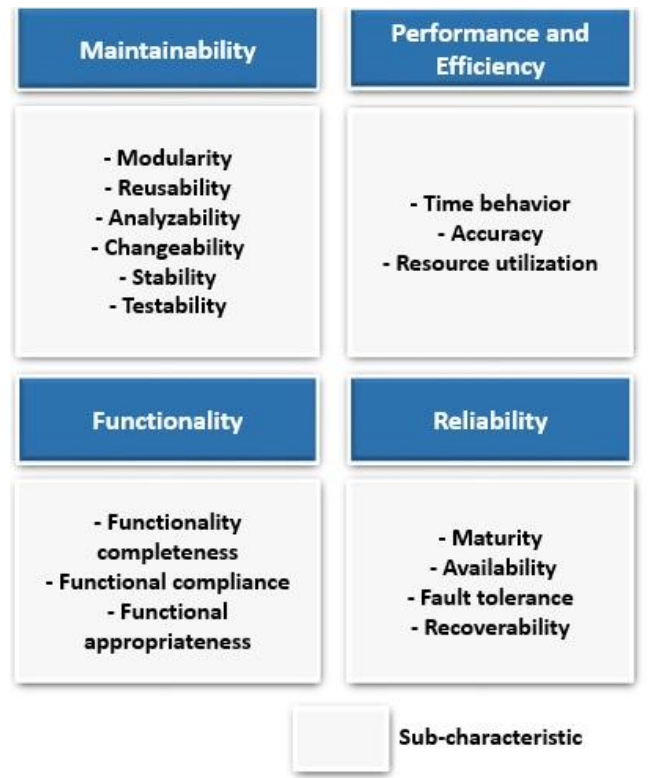

Chart 2: Definitions for the characteristics and sub-characteristics of software quality

Source: Chiuchi [10]

Another criterion that should be used to define the tool is the type of content that is inserted into the microcontent. The activity of contextualized-instructional design (CID) (2.1.5.3) presented and discussed different types of content, which were posteriorly mentioned in the activity of adapting the CID to the process of architecture of languages (2.2.3). Contents that discuss abstract concepts are better assimilated
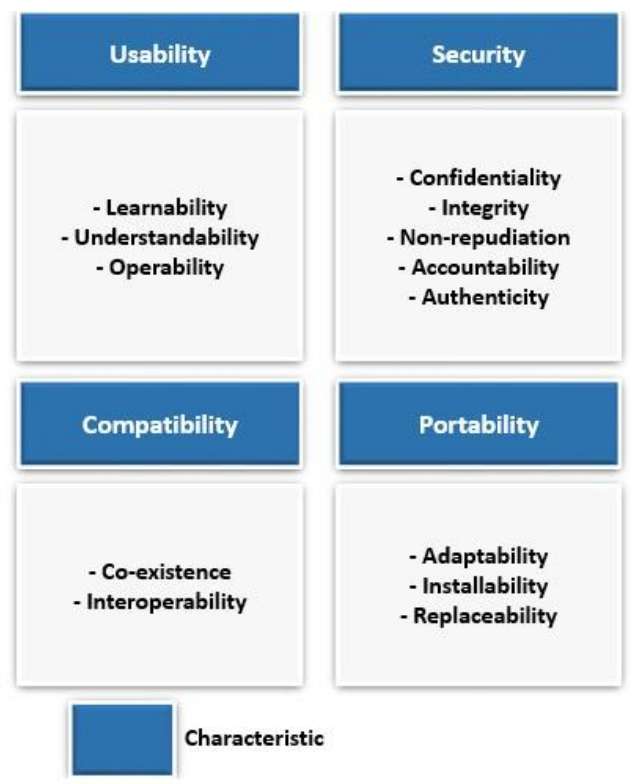

educational resource (OER) or object of learning [An OER (open educational resource) or object of learning is defined as the type of digital file (text, web page, audio, video etc.) with contents which can be used to transmit information/knowledge with educational purposes; a recognizable, standardized and interoperable unit of content; an unit of content which can be incorporated and combined with any other unit or module of a course]. Since they present characteristics of the OER/object of learning, the microcontent should be: a) designed and produced to be reutilized in many pedagogical situations; b) accessible, interoperable and of free use; c) accompanied by an open license (Creative Commons or GPL) or belong to public domain; d) produced with quality and appropriate for different contexts; g) shown by any web navigator; h) reusable and capable of readapting; i) used in different tools and platforms and integrated into multiple contexts and applications; j) capable of resisting to the evolution of technology without any risk of becoming obsolete; k) capable of migrating to new systems, versions or to a new platform.

The choice of the tools to produce educational microcontent should also be based on specific scientific criteria defined by ISO/IEC 25010:2011 [9], which presents a model of quality, with characteristics that serve as metrics for quality in software production [10]. Chart 2 shows the definitions presented in ISO/IEC 25010:2011 for the characteristics and sub-characteristics of quality. through texts, graphs, audio, figures, photos and animations; while concrete concepts are better assimilated through videos, photos, animations, figures, audio, graphs and texts. Chart 3 below indicates the capacities of some tools for developing concrete or abstract contents.

\section{Volume 4 Issue 11, November 2015}




\section{International Journal of Science and Research (IJSR) \\ ISSN (Online): 2319-7064}

Index Copernicus Value (2013): 6.14 | Impact Factor (2014): 5.611

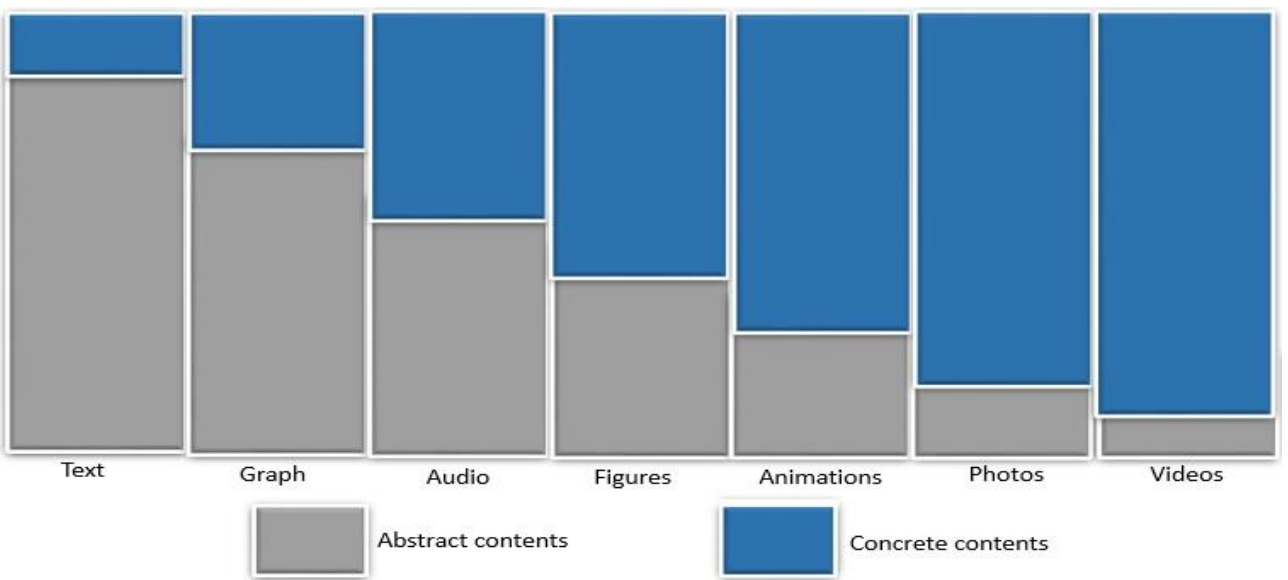

Chart 3: Tools and concept development Source: Díaz San Milla \& Ovelar Beltrán [11].

\subsubsection{Elaborate Prototype}

The main activity of the technological architecture process consists in elaborating the prototype of the microcontent. With that purpose, a specification of the prototype is required, based on the instructional design matrix elaborated in Sub-activity 2.1.5.3 of the pedagogical architecture process. However, the elaboration of the prototype must also consider the semiotic aspects previously considered in the process of architecture of languages, in addition to matching the constraints of mobile devices and the technical requisites related to the needs inherent to the activities of technological architecture production (computer science).

\section{Implementation of the proposal of instructional design}

This activity corresponds to the fourth phase of the instructional design of the microcontent, which consists in the operational execution of the design proposal discussed in the aforementioned phases of analysis, design and development. Hence, the activity applies the technological resources to the didactics established in the contextualized design developed in Sub-activity 2.1.5.3, of the pedagogical architecture process. The application will generate a prototype, the version zero of the microcontent, which is the result of the putting the instructional design proposal into practice. The computer science professionals are in charge of producing the prototype.

\subsection{Combined Activities}

In this stage, the activities of testing and validating the prototype of the educational microcontent are combined, contemplating all the proposed issues of instructional design and including pedagogical elements, semiotic aspects and language aspects. Moreover, use constraints of the chosen digital media should be pinpointed, and the requisites of interface and usability should be satisfied.

\subsubsection{Test and Validate the Prototype}

This activity of the technological architecture process consists in testing and validating the prototype of the microcontent. With that purpose, the prototype should be published, which consists in making the unit of learning (the microcontent) available for the interactors. It involves uploading content, configuring tools, setting a time for starting and ending activities, defining roles and privileges for interactors etc. In this execution phase of the prototype, the operational staff of pedagogical production, languages and computer science should work together, since the contextualized-instructional design and the technological aspects put into the microcontent will be tested and validated simultaneously by the interactors.

The test and the validation of the prototype refer to the analysis that stems from the activities proposed to interactors in the microcontents that were made available. Thus, the evaluation activities to be carried out by the pedagogical production, language and computer science staffs should verify if: a) the contents and the form how they were organized were capable of promoting interaction between the interactors that accessed them; b) the tools put into the microcontent made available were capable of promoting interaction between the interactors that accessed them; c) the microcontent produced was capable of satisfying the demands that originated its production; d) the didacticpedagogical activities adopted in microcontent production favored the construction of a comprehensive view of the theme of the microcontent for the interactors; e) the produced microcontent offered interactors an interdisciplinary and complementary view resulting from many areas of knowledge; f) the concepts inserted into the microcontent were understood/assimilated by interactors within the time limit and during the proposed activities.

Thus, the technological production staff is in charge of checking if the requisites previously defined by the processes of pedagogical architecture and architecture of languages were satisfied.

The activity of testing should lead to an alteration of the proposed design if it does not meet the interactional aspects, which should be emphasized to create meaningful learning experiences. In other words, the design is considered a planning tool that needs feedback regarding the test and validation of the microcontent. The design provides an interface with interactive resources, in addition to offering learning activities that promote the interaction of the apprentice with the contents, tools and other apprentices. For that reason, during the execution of the activity of elaborating 


\section{International Journal of Science and Research (IJSR) \\ ISSN (Online): 2319-7064}

Index Copernicus Value (2013): 6.14 | Impact Factor (2014): 5.611

the contextualized-instructional design, it was recommended observing the practices that enable interactions between the apprentice and the contents, between the apprentice and other apprentices, and between the apprentice and the specialists of the domain involved in the teaching-learning process. The instructional designer, the tutor and/or monitor and the professional that produces the content that will be inserted into the microcontent are responsible for the test and validation of the prototype.

\subsection{Evaluations of the Prototype}

In this stage, the analyses performed in Activity 2.4.1 (testing and validating the prototype) should be resumed, in an activity combined with the other processes of microcontent production. As a result, it is decided if the prototype is ready or not to be made available in a definite way for the public in general.

Thus, the evaluation of the prototype involves examining, on one side, the instructional design of the microcontent, and it corresponds to analyzing the effectiveness of the proposed solution, as well as revising the implemented strategies while observing if the expected goals are achieved.

In this stage, the elaborated microcontent and the learning results of the interactors were evaluated, which will indicate how appropriate is the instructional design. At this stage, one should follow the established relationship learners, their relationship with the content and with the domain experts involved in the teaching-learning process (in this case, the area of Embrapa technology transfer).

The evaluation should be carried out for the entire process of instructional design, starting from the phase of analysis. It encompasses performing tests of the logical and functional aspects of the elaborated microcontent, aiming at correcting mistakes and ensuring consistency and compatibility with the learning activity. The conception of the evaluation should be combined with the adopted pedagogical approach. To evaluate the quality of the microcontent, the same criteria can be adopted (precision, completeness, density, consistency, structuring, relevance, credibility and the present time) used to analyze and select the teaching material to produce the microcontent (Activity 2.1.5.1 - Analyze and select teaching material, of the pedagogical architecture process). The operational staff of pedagogical production is responsible for evaluating the prototype, reviewing and validating the products that result from each phase of the design production, such as: analysis report (diagnosis), storyboard or scripts, interfaces, follow-up reports and final evaluation reports.

The editorial staff is in charge of making the microcontent available for use in microtrainings or in objects of technology transfer (OTT), which are media which transmit technological information produced by Embrapa with the aim of disseminating and transferring information with educational purposes [12], [13].

\section{References}

[1] Filatro, A. Design instrucional na prática. São Paulo: Pearson Education do Brasil, 2008. 173 pp.

[2] Souza, M. I. F. Modelos de produção de microconteúdo educacional para ambientes virtuais de aprendizagem com mobilidade. 2013. 146 pp. Tese (Doutorado Ciências Sociais na Educação) - Faculdade de Educação, Universidade Estadual de Campinas, Campinas. Retrieved from http://www.bibliotecadigital.unicamp.br/document/?code $=000919649 \& \mathrm{fd}=\mathrm{y}$

[3] Souza, M. I. F., \& Amaral, S. F. Educational microcontent for mobile learning virtual Environments. Creative Education, 5(9), pp. 672-681, May, 2014. Retrieved from http://www.scirp.org/Journal/PaperInformation.aspx?Pap erID=46252 DOI: 10.4236/ce.2014.59079.

[4] Anastasiou, L. da G. C., \& Alves, L. P. Estratégias de ensinagem. In: Anastasiou, L. da G. C.; Alves, L. P. Processos de ensinagem na universidade: pressupostos para as estratégias de trabalho em aula. Joinville: Univille, 2003. pp 67-100. Retrieved from http:/www.ufmt.br/proeg/arquivos/2dc95cd453e52a78a 17dcc157f04dbf6.pdf

[5] Ferraz, A. P. do C. M., \& Belhot, R. V. Taxonomia de Bloom: revisão teórica e apresentação das adequações do instrumento para definição de objetivos instrucionais. Gest. Prod., São Carlos, 17(2), pp. 421-431, 2010.

[6] Santaella, L. Semiótica aplicada. 4. reimpr. São Paulo: Cengage Learning, 2008. 186 pp.

[7] Sanchez, A. V. Tecnologias para a modalidade EAD: um estudo no cenário educacional atual. E-Tech: Tecnologias para Competitividade Industrial, Florianópolis, n. Especial Educação, (2014/2), pp. 71104, 2014. Retrieved from http://revista.ctai.senai.br/index.php/edicao01/article/vie w/444

[8] Moore, M. G., \& Kearsley, G. Educação a distância: uma visão integrada. São Paulo: Cengage Learning, 2011.

[9] International Organization for Standardization. ISO/IEC 25010: 2011: systems and software engineering systems and software quality requirements and evaluation (SQuaRE) - system and software quality models. Geneva: ISO/IEC, 2011. 44 pp.

[10] Chiuchi, C. A. Diretrizes para a criação de aplicações web com ênfase em portabilidade e eficiência. 2011. 83 f. Dissertação (Mestrado em Ciência da Computação) Instituto de Biociências, Universidade Estadual Paulista, São José do Rio Preto.

[11]Díaz San Millán, E., \& Ovelar Beltrán, R. Creación de materiales didácticos digitales: características de los contenidos multimídia y herramientas de autor. [Salamanca: Universidad Salamanca], 2006. 5 pp. (Tecnologías y métodos de formación em red: tutor online). Retrieved from http://goo.gl/KnlKwB

[12] Torres, T. Z., \& Souza, M. I. F. Cultura da convergência e a perspectiva transmidiática na produção de conteúdos pedagógicos. In: Congresso Brasileiro de Ciências da Comunicação - Intercom, 34., 2011, Recife. Anais... São 


\section{International Journal of Science and Research (IJSR) \\ ISSN (Online): 2319-7064}

Index Copernicus Value (2013): 6.14 | Impact Factor (2014): 5.611

Paulo: Intercom, 2011a. Retrieved from http://www.intercom.org.br/papers/nacionais/2011/resum os/R6-2342-1.pdf

[13] Torres, T. Z., \& Souza, M. I. F. Metodologia de organização de conteúdos para a transferência de tecnologia na web 2.0. In: International Symposium on Innovation and Technology, 2., 2011, Lima, Perú. Proceedings... Lima, ISIT, 2011b. pp. 28-33.

\section{Author Profile}

2. Marcia Izabel Fugisawa Souza works at the Brazilian Agricultural Research Corporation (Embrapa) and conducts research in the field of nonformal education for virtual learning environment. Fugisawa develops digital content production research for mobile learning to support transfer of shares to the agricultural sector. She holds a $\mathrm{PhD}$ in Education from the Faculty of Education of the State University of Campinas (Unicamp), Campinas, São Paulo, Brazil.

Tércia Zavaglia Torres works at the Brazilian Agricultural Research Corporation (Embrapa) and conducts research in the areas of human and organizational development and education. Torres develops research on digital technologies to support the business process of the Company, particularly the transfer of information and technology for the agricultural sector. She has a $\mathrm{PhD}$ in Education from the Federal University of São Carlos (UFSCar), São Carlos, São Paulo, Brazil. 